\title{
Percutaneous Pinning for Displaced Supracondylar Humerus Fractures in Pediatric Age Group: Comparison between Lateral Pinning Versus Crossed Pinning Techniques
}

\author{
Sajid Younus, Asif Peracha, Syed Kamran Ali Shah*, Faizan Iqbal, Nouman Memon and Muhammad Rahim \\ Najjad
}

Department of Orthopedics, Liaquat National Hospital, Pakistan

Submission: April 16, 2018; Published: April 26, 2018

*Corresponding author: Dr. Syed Kamran Ali Shah, Department of Orthopedics, K-Block, Liaquat National Hospital, Stadium road, Karachi, Pakistan, Tel: 0322-3077485; Email: drkami1405@gmail.com

\begin{abstract}
Objective: To assess and compare the outcome of crossed pinning versus lateral pinning techniques for operating pediatric displaced supracondylar humerus fractures.

Materials and methods: This is a prospective observational study conducted at orthopedic department of a tertiary care hospital from January 2014 to December 2016. Total of 110 patients were registered in this study with displaced supracondylar fracture of humerus from 2-12 years of age group. All the children presented at emergency or out patients department having displaced supracondylar humeral fractures underwent for physical examination and radiological assessment, patients with Gartland type II and III were included in this study and patients with open fracture and vascular injury or neurological deficit at presentation were excluded. Children were divided into two groups according to the technique of percutaneous pinning; (A) Lateral pinning $(n=52)$ versus (B) Crossed pinning $(n=58)$. Both groups were compared with respect to gender proportion, mean age, fracture type, time between injury and surgery. The clinical outcome evaluated at $6^{\text {th }}$ month follow up was range of motion while the radiological outcome was fracture displacement during the follow up, union and change in Baumann's angle at union. The complications (ulnar nerve neuropraxia or injury and pin tract infection) were also evaluated.
\end{abstract}

Results: Total of 110 patients were included in the study (lateral pinning $n=52$ and crossed pinning $n=58$ ). The fractures treated with lateral pinning had inferior radiological outcome as compared to the crossed pinning technique while the difference in ulnar nerve neuropraxia between the two configurations was statistically insignificant.

Conclusion: In the light of above study we concluded that fixation with crossed pins are superior for treating displaced supracondylar humeral fractures. However, cautions should be undertaken to avoid iatrogenic ulnar nerve injury during medial pin insertion.

Keywords: Supracondylar fractures; Lateral pinning; Crossed pinning

\section{Introduction}

Supracondylar humerus fractures are among the most common fractures in children, usually occurring before 7 years of age [1]. These fractures are extension type or flexion type, the extension type is more common [2,3]. According to displacement, Gartland classification divides these fractures into three types; Type I is a nondisplaced fracture, type II is a displaced fracture with intact posterior cortex, type III is a displaced fracture with no cortical contact [4]. Type I are treated in above elbow cast with serial radiographs to check for displacement. Type II and III are usually treated by closed reduction and percutaneous pinning. Open reduction is done in case of failed closed reduction [5].

There is an ongoing debate among the orthopedic surgeons about the configuration of pin placement in these fractures. Two widely used patterns are; 2 lateral wires or one lateral and one medial wire in cross pattern. The issues are mechanical stability and risk of iatrogenic ulnar nerve injury [6,7]. Sibinski et al. [8] suggested the pattern of 2 lateral wires as safer approach in light of their study reporting similar outcome in terms of mechanical stability of the two configurations while lower risk of ulnar nerve injury with lateral pinning technique. Zamzam et al. [9] concluded that crossed wires should be used for displaced type III fractures due to inferior mechanical stability with lateral pinning configuration. A further systematic review of randomized controlled trials comparing the two wire configurations in extension type Gartland type III fractures however found no difference in clinical or radiological outcomes [10].

This study aimed to evaluate and compare the outcome of the crossed and the lateral pinning configurations in the 
management of pediatric displaced supracondylar humeral fractures and also comparing the complication rate of the two techniques.

\section{Material and Methods}

This is a prospective observational study conducted at orthopedic department of Liaquat National Hospital \& medical college, a tertiary care hospital from January 2014 to December 2016. Total of 110 patients were registered in this study with displaced supracondylar fracture of humerus from 2-12 years of age group. All the children presented at emergency or out patients department having displaced supracondylar humeral fractures underwent for physical examination and radiological assessment, patients with Gartland type II and III were included in this study and patients with open fracture and vascular injury or neurological deficit at presentation were excluded. Children were divided into two groups according to the technique of percutaneous pinning; (A) Two wires inserted from lateral epicondyle $(n=52)$ and (B) Two wires inserted in crossed pattern $(n=58)$. Both groups were compared with respect to gender proportion, mean age, fracture type, time between injury and surgery and cases of open reduction.

Standard surgical technique was used in all patients. All the patients underwent general anesthesia followed by closed/ open reduction and percutaneous pinning. The surgeon selected the pin size to be used according to the age of the child and the size of the arm (usually $1.6 \mathrm{~mm}$ for younger children and 1.8-2.0mm for older children). Before the K-wire was inserted from the medial side, medial epicondyle was palpated with thumb. Later, the thumb was shifted posteriorly to protect the ulnar nerve. In case of elbow swelling, an approximately $10 \mathrm{~mm}$ small incision was also used to allow safer pin placement over the medial epicondyle. The pin ends were bent outside the skin, and an above elbow back slab was applied with approximately 90 degrees of elbow flexion and neutral forearm rotation. The children were discharged home when comfortable (usually after 1-2 days). Patients had follow up at $1^{\text {st }}$ week, $4^{\text {th }}$ week, $6^{\text {th }}$ week, $3^{\text {rd }}$ month and 6th month for clinical assessment of pin sites, possible iatrogenic neurological deficit and its progress and serial radiographs to assess union and decision to remove the splint and wires, and commencing range of motion. At $1^{\text {st }}$ week in the clinic after surgery, radiographs were obtained in both anterioposterior and lateral planes. If these were acceptable, the child was seen again at $4^{\text {th }}$ week of surgery; radiographs were obtained on cast removal. When acceptable healing was confirmed, pins were removed in the clinic and encouraged motion around elbow.

The final clinical outcome evaluated at $6^{\text {th }}$ month follow up was range of motion. The radiological outcome was fracture displacement during the follow up, indicated by translation, rotation or angulation at the fracture site, union and change in Baumann's angle at union relative to the immediate postoperative Baumann's angle. The main complications evaluated were ulnar nerve neuropraxia or injury and pin tract infection.
The clinical and radiological outcome and the complications of the two techniques were compared through statistical analysis using SPSS version 20 by applying Chi-square test. P-value $<0.05$ was considered as significant.

\section{Results}

110 children were included in the study after matching of the groups according to gender proportion, mean age, fracture type, time between injury and surgery and following the inclusion criteria. 52 patients were operated with lateral pinning technique and 58 with crossed pinning method. The demographics, fracture type and duration between injury and surgery are shown in Table 1 . The mean time of union was $4.8 \pm 1.3$ weeks in lateral pinning group and $4.6 \pm 1.1$ weeks in crossed pinning group.

Table 1: Demographics and fracture type $(n=110)$.

\begin{tabular}{|c|c|c|c|}
\hline Parameters & $\begin{array}{c}\text { Lateral } \\
\text { Pinning group } \\
\text { (n=52) }\end{array}$ & $\begin{array}{c}\text { Crossed } \\
\text { Pinning Group } \\
\text { (n=58) }\end{array}$ & P-value \\
\hline $\begin{array}{c}\text { Mean age in } \\
\text { years( } \pm \text { SD) }\end{array}$ & $6.76( \pm 2.81)$ & $7.12( \pm 2.24)$ & 0.081 \\
\hline $\begin{array}{c}\text { Number of } \\
\text { female children } \\
(\%)\end{array}$ & $19(36.53 \%)$ & $22(38.50 \%)$ & 0.115 \\
\hline $\begin{array}{c}\text { Fracture types } \\
\text { Gartland II (\%) } \\
\text { Gartland III } \\
\text { (\%) }\end{array}$ & $16(30.80 \%)$ & $19(32.76 \%)$ & 0.074 \\
\hline $\begin{array}{c}\text { Mean Duration } \\
\text { between injury } \\
\text { and surgery in } \\
\text { days ( } \pm \text { SD) }\end{array}$ & $2.5( \pm 0.91)$ & $39(67.24 \%)$ & 0.078 \\
\hline
\end{tabular}

$\mathrm{SD}=$ Standard deviation.

Table 2: Radiological outcome $(n=110)$.

\begin{tabular}{|c|c|c|c|}
\hline Parameters & $\begin{array}{c}\text { Lateral } \\
\text { Pinning Group } \\
\text { (n=52) }\end{array}$ & $\begin{array}{c}\text { Crossed } \\
\text { Pinning Group } \\
\text { (n=58) }\end{array}$ & P-value \\
\hline $\begin{array}{c}\text { Mean time } \\
\text { of union in } \\
\text { weeks( } \pm \text { SD) }\end{array}$ & $4.81( \pm 1.33)$ & $4.6( \pm 1.1)$ & 0.233 \\
\hline $\begin{array}{c}\text { Patients } \\
\text { with fracture } \\
\text { displacement } \\
\text { during the } \\
\text { follow up (\%) }\end{array}$ & $8(15.38 \%)$ & $2(3.45 \%)$ & $0.002^{*}$ \\
\hline $\begin{array}{c}\text { Patients with } \\
\text { change in } \\
\begin{array}{c}\text { Baumann's } \\
\text { angle at union } \\
(\%)\end{array}\end{array}$ & $4(7.70 \%)$ & $1(1.72 \%)$ & $0.004^{*}$ \\
\hline
\end{tabular}

$\mathrm{SD}=$ Standard deviation.

${ }^{*} p$-value $<0.05$ is considered significant.

During the follow up, 8 patients in the lateral entry group had fracture displacement. Two of them had posterior displacement of distal fragment while six of them had rotation. The difference in fracture displacement among the two groups was statistically 
significant $(\mathrm{p}=0.002)$ (Table 2). The comparison of change in Baumann's angle at union relative to the postoperative angle is shown in Table 2. This radiological parameter had also inferior figures in lateral entry group as more patients in this group had change in Baumann's angle $(\mathrm{p}=0.004)$.

The final clinical outcome at 6 months follow up was assessed by examining range of motion at the affected elbow. 99 children achieved full range of motion at 6 months. The remaining 11 patients ( 5 of them had lateral pinning and 6 had crossed wiring) were advised to continue physiotherapy. The difference in this parameter was statistically insignificant among the two groups ( $p=0.12$ ). Table 3 is showing the complications observed during the follow up. Three patients $(2.7 \%)$ had ulnar nerve injury which all eventually recovered. The difference in this important complication was statistically insignificant $(\mathrm{p}=0.082)$. Four patients had superficial pin site infection during the follow up which was treated through oral antibiotics.

Table 3: Complications

\begin{tabular}{|c|c|c|c|}
\hline Complications & $\begin{array}{c}\text { Lateral } \\
\text { Pinning } \\
\text { Group (n=52) }\end{array}$ & $\begin{array}{c}\text { Crossed } \\
\text { Pinning } \\
\text { Group (n=58) }\end{array}$ & P-value \\
\hline $\begin{array}{c}\text { UInar nerve } \\
\text { neuropraxia (\%) }\end{array}$ & $2(3.85 \%)$ & $1(1.72 \%)$ & 0.082 \\
\hline $\begin{array}{c}\text { Pin tract } \\
\text { infections (\%) }\end{array}$ & $2(3.84 \%)$ & $2(3.45 \%)$ & 0.322 \\
\hline
\end{tabular}

\section{Discussion}

The standard treatment of displaced supracondylar humerus fracture is percutaneous k-wire fixation after reduction under image intensification [11]. The success of this treatment lies in achieving and maintaining reduction until union of the fracture and avoiding possible complications of this intervention. Despite the implication of this standard treatment for a long period of time, there is no clear consensus in the community of orthopedic surgeons on the optimal pin configuration [12]. The prime debate is between the two lateral pinning methods or one lateral and one medial pin in cross configuration. The two most important aspects which have been studied are maintenance of fracture stability till union and avoiding the iatrogenic ulnar nerve injury [13].

Advocates of crossed pin fixation point out biomechanical studies showing that this configuration gives better stability than lateral pins $[14,15]$. On the other hand, the risk of iatrogenic ulnar nerve injury is probably more in crossed pattern $[16,17]$.

In our study, 8 out of 52 patients had fracture displacement in lateral pinning group while 4 had change in Baumann's angle at union which was significantly an inferior outcome in terms of fracture stability as compared to the crossed configuration. Coinciding with our result, Karim MA et al. [18] in his prospective randomized controlled study treated 60 patients with supracondylar fractures, half of them with lateral pinning technique and the remaining 30 patients with crossed pinning configuration. He observed fracture instability in terms of displacement and rotation in 6 out of 60 (10\%) children, all had lateral pinning fixation. Similarly, Zamzam et al. [9] in his retrospective study reported the outcomes of 37 children operated with two lateral pins and 37 children with crossed pinning technique. He also observed early postoperative fracture displacement in 9 children; all of them had two lateral wires fixation.

On the contrary, Sibinski et al. [8] concluded in his study of 131 patients operated through both pinning configurations that the fracture stability is similar with the two configurations. In a prospective randomized controlled study performed by Kocher et al. [6] to compare lateral entry pins with medial- and lateralentry pin fixation for completely displaced SC humeral fractures in children, there were no patients in either group that had a major loss of reduction. There were no significant differences between the rates of mild loss of reduction, which occurred in 6 of the 28 patients treated with lateral entry and 1 of the 24 patients treated with medial and lateral entry $(p=0.107)$. In another prospective RCT by Maity et al. [19], there were no differences between the 2 groups regarding loss of reduction grading.

In our study, 3 children (2.7\%) developed ulnar nerve deficit which eventually recovered in all cases. Although the etiology of the ulnar nerve injury that occurred in the lateral group remains unclear, the authors attribute it to either over drilling or over traction during manipulation The difference between the two groups with respect to this important complication was not statistically significant $(\mathrm{p}=0.082)$ in our study. In the study by Devkota et al. [20], 7 of the 79 patients in the crossed pinning group (6.86\%) developed ulnar nerve injury. In another study performed by Chakraborty et al. [21], 4 patients (4.34\%) developed ulnar nerve injury; all were from the crossed pinning group. All patients followed in our study regained full range of motion at the affected elbow at 6 months except 11 children. The difference in this complication (elbow stiffness) between the two groups was not statistically significant $(\mathrm{p}=0.012)$. The result is similar to that reported by Karim MA et al. [18] ( $p=0.083)$.

The incidence of pin tract infection in our study was 4/110 $(3.63 \%)$ with no significant difference between the two groups $(\mathrm{p}=0.322)$. This finding coincides with Devkota et al. [20], who reported 8 patients $(\mathrm{p}=7.84 \%)$ developing pin tract infection in his study with insignificant difference of pin tract infection between the two pinning configurations.

\section{Conclusion}

In conclusion, we found that the crossed entry pin fixation technique provides more stability than the lateral entry pin fixation technique in management of displaced supracondylar fractures of the humerus in children. So, fixation by crossed pins is suggested for treating these fractures. However, every effort should be made to avoid iatrogenic ulnar nerve injury while inserting the medial pin either by palpating the ulnar nerve at 
the time of pinning or making a small incision over the medial epicondyle in cases of severe elbow swelling.

\section{References}

1. Korompilias AV, Lykissas MG, Mitsionis GI, Kontogeorgakos VA, Manoudis G, et al. (2009) Treatment of pink pulse less hand following supracondylar fractures of the humerus in children. Int Orthop 33(1): 237-241.

2. Mahan ST, May CD, Kocher MS (2007) Operative management of displaced flexion supracondylar humerus fractures in children. J Pediatr Orthop 27(5): 551-556.

3. De las Heras J, Duran D, de la Cerda J, et al. (2017) Supracondylar fractures of the humerus in children. Clin Orthop Relat Res 432: 57-64.

4. Gartland JJ (1959) Management of supracondylar fractures of the humerus in children. Surg Gynecol Obstet 109(2): 145-154.

5. Omid R, Choi PD, Skaggs DL (2008) Supracondylar humeral fractures in children. J Bone Joint Surg Am 90(5): 1121-1132.

6. Kocher MS, Kasser JR, Waters PM, Bae D, Snyder BD, et al. (2007) Lateral entry compared with medial and lateral entry pin fixation for completely displaced supracondylar humeral fractures in children. A randomized clinical trial. J Bone Joint Surg Am 89: 706-712.

7. Lee SS, Mahar AT, Miesen D, Newton PO (2002) Displaced pediatric supracondylar humerus fractures: biomechanical analysis of percutaneous pinning techniques. J Pediatr Orthop 22: 440-443.

8. Sibinski M, Sharma H, Sherlock DA (2006) Lateral versus crossed wire fixation for displaced extension supracondylar humeral fractures in children. Injury 37(10): 961-965.

9. Zamzam MM, Bakarman KA (2009) Treatment of displaced supracondylar humeral fractures among children: crossed versus lateral pinning. Injury 40(6): 625-630.

10. Yousri T, Tarassoli P, Whitehouse M, Monsell F, Khan WS (2012) Systematic review of randomized controlled trials comparing efficacy of crossed versus lateral K-wire fixation in extension type Gartland type III supracondylar fractures of the humerus in children. Ortop Traumatol Rehabil 14(5): 397-405.

11. Brauer CA, Lee BM, Bae DS, Waters PM, Kocher MS, et al. (2007) A systematic review of medial and lateral entry pinning versus lateral entry pinning for supracondylar fractures of the humerus. J Pediatr Orthop 27(2): 181-186.
12. Foead A, Penafort R, Saw A, Sengupta S (2004) Comparison of two methods of percutaneous pin fixation in displaced supracondylar fractures of the humerus in children. J Orthop Surg (Hong Kong) 12(1): 76-82.

13. Zionts LE, McKellop HA, Hathaway R (1994) Torsional strength of pin configurations used to fix supracondylar fractures of the humerus in children. J Bone Joint Surg Am 76(2): 253-256.

14.Zenios M, Ramachandran M, Milne B, Little D, Smith N, et al. (2007) Intraoperative stability testing of lateral-entry pin fixation of pediatric supracondylar humeral fractures. J Pediatr Orthop 27(6): 695-702.

15. Lee KM, Chung CY, Gwon DK, Sung KH, Kim TW, et al. (2012) Medial and lateral crossed pinning versus lateral pinning for supracondylar fractures of the humerus in children: decision analysis. J Pediatr Orthop 32(2): 131-138.

16. Khwaja MK, Khan WS, Ray P, Park DH (2017) A Retrospective Study Comparing Crossed and Lateral Wire Configurations in Paediatric Supracondylar Fractures. Open Orthop J 11: 432-438.

17. Krusche-Mandl I, Aldrian S, Köttstorfer J, Seis A, Thalhammer G, et al. (2012) Crossed pinning in paediatric supracondylar humerus fractures: a retrospective cohort analysis. International orthopaedics 36(9): 1893-1198.

18. Karim MA, Hosny A, Abdelatif NM, Hegazy MM, Awadallah WR, et al. (2016) Crossed Wires Versus 2 Lateral Wires in Management of Supracondylar Fracture of the Humerus in Children in the Hands of Junior Trainees. J Orthop Trauma 30(4): e123-e128.

19. Maity A, Saha D, Roy DS (2012) A prospective randomised, controlled clinical trial comparing medial and lateral entry pinning with lateral entry pinning for percutaneous fixation of displaced extension type supracondylar fractures of the humerus in children. J Orthop Surg Res 7: 6 .

20. Devkota P, Khan JA, Acharya BM (2008) Outcome of supracondylar fractures of the humerus in children treated by closed reduction and percutaneous pinning. J Nepal Med Assoc 47: 66-70.

21. Chakraborty MK, Onta PR, Sathian B (2011) Displaced supracondylar fracture of humerus in children treated with crossed pin versus lateral pin: a hospital based study from Western Nepal. West Nepal J Clin Diagn Res 5(6): 1260-1263.

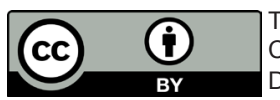

This work is licensed under Creative Commons Attribution 4.0 License DOI: 10.19080/OROAJ.2018.11.555817

\section{Your next submission with Juniper Publishers will reach you the below assets}

- Quality Editorial service

- Swift Peer Review

- Reprints availability

- E-prints Service

- Manuscript Podcast for convenient understanding

- Global attainment for your research

- Manuscript accessibility in different formats

( Pdf, E-pub, Full Text, Audio)

- Unceasing customer service

\section{Track the below URL for one-step submission}

https://juniperpublishers.com/online-submission.php 